Cardiac catheterisation and angiography have a purpose in making or confirming the diagnosis and in excluding other causes of pulmonary hypertension, particularly thromboembolism, in which major pulmonary artery branches will be seen to be occluded. The procedure carries some risknormally, the adverse effect of possible vagally induced bradycardia and peripheral vasodilatation caused by contrast media. ${ }^{5}$ These hazards may be reduced by prophylactic treatment with atropine and with phenylephrine immediately before or with the contrast injection.

Pulmonary arterial hypertension may develop secondary to thrombotic occlusion of pulmonary veins and venules. ${ }^{6}$ This form of secondary pulmonary hypertension occurs at any age but is most common in childhood and pursues a more rapid and routinely fatal course than does the primary form. Pulmonary veno-occlusive disease may be suspected when a patient with unexplained pulmonary hypertension has a hazy background in the plain chest radiograph. Clouding may be patchy or the films may suggest pulmonary venous hypertension or interstitial pulmonary fibrosis. Intrinsic lung disease may be excluded by pulmonary function tests and other causes of pulmonary venous hypertension by echocardiography and cardiac catheterisation. Lung biopsy will confirm the diagnosis, but the possible hazards of this procedure must be weighed against a negligible gain-knowledge of the dismal prognosis-since there is no treatment known to influence the course of pulmonary veno-occlusive disease.

The aetiology of primary pulmonary hypertension is unknown but is probably diverse. An association with pregnancy or female hormones is apparent from the sex and age of most patients, but the mechanisms are unknown. ${ }^{7} \mathrm{~A}$ familial tendency is not uncommon especially in childhood. ${ }^{8}$ An association has been noted with Raynaud's phenomenon ${ }^{9}$ and with connective tissue disorder, particularly the so-called "mixed connective tissue disease," and very rarely also with cirrhosis of the liver. ${ }^{10} \mathrm{An}$ epidemic of primary pulmonary hypertension in Switzerland a few years ago was attributed to the use of the slimming drug aminorex fumarate, ${ }^{11}$ which has chemical similarities with the crotalaria alkaloids (present in ragwort), which can induce pulmonary hypertension in rats. Though pulmonary microembolism has been suggested as a cause of primary pulmonary hypertension (in contrast with macroembolism in large vessel thromboembolic pulmonary hypertension), there is no evidence to support this and the uniform perfusion found on lung scans is against it. ${ }^{12}$

The usual clinical course is progression from the onset of symptoms to death within two to 10 years, but survival for much longer periods has been reported ${ }^{13} 14$ as also has regression of pulmonary hypertension even from an advanced stage. ${ }^{15}$ These examples of regression could not be ascribed to treatment, and none has shown itself to be effective. Anticoagulants have been given, partly because of the microembolism theory and partly because the low cardiac output predisposes to late thromboembolic complications. Some patients show a fall in pulmonary artery pressure in response to the injection of acetylcholine directly into the pulmonary artery ${ }^{16}$; on that basis many vasodilator substances have been tried for long-term treatment of these patients, but all dilate the systemic vascular bed and may cause a dangerous drop in blood pressure. Drugs used have included isoprenaline, tolazoline, hydralazine, diazoxide, and nifedipine. Long-term oxygen treatment may have a limited place. More radicaland more dangerous but equally useless have been sympathectomy and the creation of a shunt at atrial level (on the basis that patients with a reversed interatrial shunt survive longer).
Nevertheless, the fact that seemingly spontaneous regression of pulmonary hypertension does occur, however rarely, encourages the search for an effective treatment. Unhappily, the exciting thought of using prostaglandins in these patients has proved disappointing; research continues.

1 Wood P. Congenital heart disease: a review of its clinical aspects in the light of experience gained by means of modern techniques. $\mathrm{Br} \mathrm{Med} \mathfrak{F}$ 1950 ;ii:693-8.

2 Wood P. Pulmonary hypertension. Br Med Bull 1952;8:348-53.

${ }^{3}$ Evans W, Short DS, Bedford DE. Solitary pulmonary hypertension. $\mathrm{Br}$ Heart $\mathcal{F} 1957$;19:93-116.

4 Heath D, Whitaker W, Brown JW. Idiopathic pulmonary hypertension. Br Heart f 1957;19:83-92.

Keane JF, Fyler DC, Nadas AS. Hazards of cardiac catheterization in children with primary pulmonary vascular obstruction. Am Heart $\mathcal{f}$ $1978 ; 96: 556-7$.

6 Thadani U, Burrow C, Whitaker W, Heath D. Pulmonary veno-occlusive disease. $Q \mathcal{F}$ Med $1975 ; 44: 133-59$.

7 Kleiger RE, Boxer M, Ingham RE, Harrison DC. Pulmonary hypertension in patients using oral contraceptives. A report of six cases. Chest 1976; 69:143-7.

${ }^{8}$ Parry WR, Verel D. Familial primary pulmonary hypertension. Br Heart $\mathcal{F}$ 1966 ;28:193-8.

- Winters W, Joseph R, Learner N. Primary pulmonary hypertension and Raynaud's phenomenon. Arch Intern Med 1964;114:821.

10 Segel N, Kay JM, Bayley TJ, Paton A. Pulmonary hypertension with hepatic cirrhosis. Br Heart $\mathcal{F} 1968$;30:575-8.

11 Follath F, Burkart F, Schweizer W. Drug-induced pulmonary hypertension? Br Med F $1971 ; \mathrm{i}: 265-6$.

12 Wilson AG, Harris CN, Lavender JP, Oakley CM. Perfusion lung scanning in obliterative pulmonary hypertension. Br Heart $\mathcal{f} 1973 ; 35$ : 917-30.

13 Trell E. Benign, idiopathic pulmonary hypertension? Two further cases of unusually long duration. Acta Med Scand 1973;193:137-43.

14 Suarez D, Sciandro EE, Llera JJ, Perosio AM. Long-term follow-up in primary pulmonary hypertension. Br Heart F 1979;41:702-8.

15 Bourdillon PDV, Oakley CM. Regression of primary pulmonary hypertension. Br Heart F 1976;38:264-70.

16 Samet P, Bernstein WH, Widrich J. Intracardiac infusion of acetylcholine in primary pulmonary hypertension. Am Heart $\mathcal{F} 1960 ; 60$ :433-9.

\section{Management of hepatic encephalopathy}

The importance of the normal functions of the liver becomes clear when disease interferes with them. The fluid and electrolyte balances become disturbed, leading to ascites, oedema, hypovolaemia, and hypokalaemia, often in association with renal impairment. Haemorrhage may occur from oesophageal varices and be exacerbated by deficiency of clotting factors. Hypoglycaemia may be troublesome. The patient is unusually susceptible to infections.

Some of the most striking changes are those affectingmental and nervous function. The exact cause of hepatic encephalopathy remains problematical, but its management is of prime importance in many patients with liver failure. Hepatic encephalopathy comprises various disturbances, including paraplegia, Parkinsonism, dementia, and different types of clouding of consciousness. There is no pathognomonic anatomical brain lesion, though oedema and astroglial proliferation are characteristic.

Three patterns of hepatic encephalopathy are recognisable. Firstly, portasystemic encephalopathy results from shunting round the liver of venous blood from the gut; it is often secondary to cirrhosis or may be surgically induced. Secondly, patients with established cirrhosis may develop temporary encephalopathy in association with an infection, injudicious drug treatment, or gastrointestinal bleeding. Finally, fulminant hepatic failure may follow viral hepatitis, drug-induced 
damage, or alcoholic liver disease and may lead to coma and death.

The cause of encephalopathy is usually accepted as the passive transfer of toxins from the gut to the brain, though a possible second factor is impairment of hepatic synthesis of active neurotropic substances. Among the biochemical changes suggested as causes of the encephalopathy have been increased concentrations of ammonia and of aromatic amino-acids, a decrease in branched-chain amino-acids and increases in serotonin and short-chain fatty acids, the presence of false neurotransmitters such as octopamine and phenylethanolamine, and altered metabolism of prostaglandins and neuroendocrine peptides.

The established treatment for controlling encephalopathy includes emptying the bowel by purgatives or enemas and a diet low in protein. Manoeuvres to alter the colonic flora and decrease the uptake of toxins are also useful, and lactulose is the drug of choice. Neomycin is similarly effective, but its side effects prohibit more than brief use. Colonic exclusion by ileostomy is rarely required nowadays.

Newer treatments for hepatic encephalopathy include levodopa, bromocriptine, charcoal haemoperfusion, and liver transplantation. Levodopa may work by replenishing the true brain neurotransmitters, releasing other competing transmitters, or by stopping formation of methylamines. First used in massive dosage in fulminant hepatic failure 10 years ago, it had a striking arousal effect in the patient treated. ${ }^{1}$ Side effects limit the dose that can be given, but levodopa has been used with apparent benefit in both acute and chronic encephalopathy. ${ }^{2-4}$ As the disease itself is heterogeneous it is difficult to assess in these studies how many of the recoveries were spontaneous. An attempt to throw light on the issue was a report of the use of levodopa with or without a decarboxylase inhibitor in 75 patients with cirrhosis. ${ }^{5}$ No useful effect was shown. Nevertheless, as these patients were predominantly alcoholics who had developed encephalopathy because of gastrointestinal bleeding or alcoholic intoxication, this superbly conducted prospective double-blind randomised placebo-controlled trial could be criticised on the grounds that the patients were quite the wrong sort. Furthermore, the effects of levodopa do not persist and are not seen at all in severe chronic encephalopathies, so this treatment remains of unproved value.

Bromocriptine is a dopamine agonist which was found to be effective in combination with lactulose in six patients with intractable stable severe encephalopathy. ${ }^{6}$ It offered no advantage in another study of seven less severely affected patients, in whom it was used as an alternative to standard treatment. ${ }^{\text {? }}$ Like levodopa, bromocriptine may have some place in the management of hepatic encephalopathy, but use of these drugs is strictly a research project at present.

Charcoal haemoperfusion and liver transplantation are responses to the desperate condition of many patients with severe liver disease. They certainly have an impact on encephalopathy in the short term, but the effect on survival is still being evaluated. In most patients standard treatment with diet, purgation, lactulose, and avoidance of unnecessary psychotropic drugs are the routine-and probably the bestremedies for chronic hepatic encephalopathy. Other measures may become useful adjuncts, but there have been too many false dawns already.

\footnotetext{
${ }^{1}$ Parkes JD, Sharpstone P, Williams R. Levodopa in hepatic coma. Lancet 1970;ii:1341-3.

2 Abramsky O, Goldschmidt Z. Treatment and prevention of acute hepatic encephalopathy by intravenous levodopa. Surgery 1974 ;75:188-93.
}

${ }^{3}$ Lunzer M, James IM, Weinman J, Sherlock S. Treatment of chronic hepatic encephalopathy with levodopa. Gut 1974;15:555-61.

4 Fischer JE, Funovics JM, Falcao HA, Wesdorp RIC. L-dopa in hepatic coma. Ann Surg 1976;183:386-91.

${ }^{5}$ Michel H, Solere M, Granier P, et al. Treatment of cirrhotic hepatic encephalopathy with L-dopa. A controlled trial. Gastroenterology 1980; 79:207-11.

${ }^{6}$ Morgan MY, Jakobovits AW, James IM, Sherlock S. Successful use of bromocriptine in the treatment of chronic hepatic encephalopathy. Gastroenterology 1980;78:663-70.

7 Uribe M, Farca A, Márquez MA, Garcia-Ramos G, Guevara L. Treatment of chronic portal systemic encephalopathy with bromocriptine. A double-blind controlled trial. Gastroenterology 1979;76:1347-51.

\section{Metabolic obesity?}

Few people nowadays would sympathise with the position of the affluent Victorian mill owner haranguing his impoverished workforce on the virtue of thrift: in these enlightened times we realise that the low wages he paid were an important cause of poverty. Similarly, our views on the cause of obesity have become more liberal: many fat people eat no more than many thin people, so that obesity cannot be ascribed entirely to the vices of sloth and gluttony. Nevertheless, the laws of thermodynamics apply to man as much as to steam engines, and no organism can store energy as fat unless its intake of energy exceeds its output. The search is on, therefore, for ways in which obese people run at a lower energy cost than the rest of the population.

In general, when the energy expenditure of obese individuals is compared with that of lean, the obese ones have the higher metabolic rate. ${ }^{1}$ In theory, a subgroup of obese people, perhaps characterised by a family history of obesity or obesity of early onset, might be found to have an unusually low metabolic rate; no such group has been identified. ${ }^{2}$ There is some evidence that obese people are less physically active than lean ones, but a given level of activity requires more energy from a heavy person than a light one so that physical inactivity cannot provide a realistic basis for substantial savings on energy expenditure. ${ }^{3}$

Recent work on the obese (ob/ob) mouse has shown that an important factor in its genetically determined obesity is a decreased thermogenic response to cold. ${ }^{4}$ In circumstances in which the lean animal would increase heat production the $\mathrm{ob} / \mathrm{ob}$ mouse does not. The result is that if it does not die of hypothermia it has more energy to lay down as fat. The biochemical defect which leads to this impaired thermogenic response has been traced to brown fat. ${ }^{5}$ Is there an analogous metabolic defect in at least some obese humans?

Probably there is. A research group in Lausanne has shown that the increase in metabolic rate after an oral load of $50 \mathrm{~g}$ glucose was smaller in obese than in lean persons. ${ }^{6}$ After an infusion of noradrenaline (which mimics the action of coldinduced thermogenesis) obese people showed a smaller response than lean people, as did people of normal weight who had formerly been obese. ${ }^{7}$ There is still controversy about the relevance of brown fat to these reactions in adult man: the mouse is a small animal which needs an efficient heat-generating apparatus to survive, but keeping his body temperature constant is less of a struggle for a large animal such as man.

The latest suggestion for an energy-saving metabolism which may be relevant to obesity comes from Boston. ${ }^{8}$ A study there showed that the red cells of obese people had fewer sodium-potassium pump units than red cells from lean 